\title{
BLUEBIRDS AT ABERNETHY: HISTORY AND 1988 RESULTS
}

RONALD A. BITTNER, Box 97, Abernethy, Saskatchewan. SOA 0A0

Abernethy is located in southeastern Saskatchewan, $130 \mathrm{~km}$ from Manitoba and $190 \mathrm{~km}$ from the United States. It is within the modern nesting range of both the Mountain and Eastern bluebird but the latter is much less common here. I have not yet had an Eastern Bluebird in my houses, so this article refers only to the Mountain Bluebird.

\section{A Bit of History}

Bluebirds were unknown in this area until the early 1940s according to what I was told by my parents. About that time my father saw his first bluebirds while he was getting the cows from a partly wooded pasture.
My first experience with bluebirds occurred about 1945 when I was growing up on our farm $4 \mathrm{mi}$. southeast of Abernethy. One day a pair of bluebirds appeared on the fence near the woodpile. Somehow I knew that bluebirds would nest in a bird house. Perhaps I learned this from our new Birds of Canada which my mother ordered from Eaton's Catalog. ${ }^{1}$ I made a bird house out of an apple box and mounted it on a lone aspen near the yard. The bluebirds used it that year. Their nesting material was mainly strips of fine, soft bark from the woodpile. Most nests are constructed with grasses.

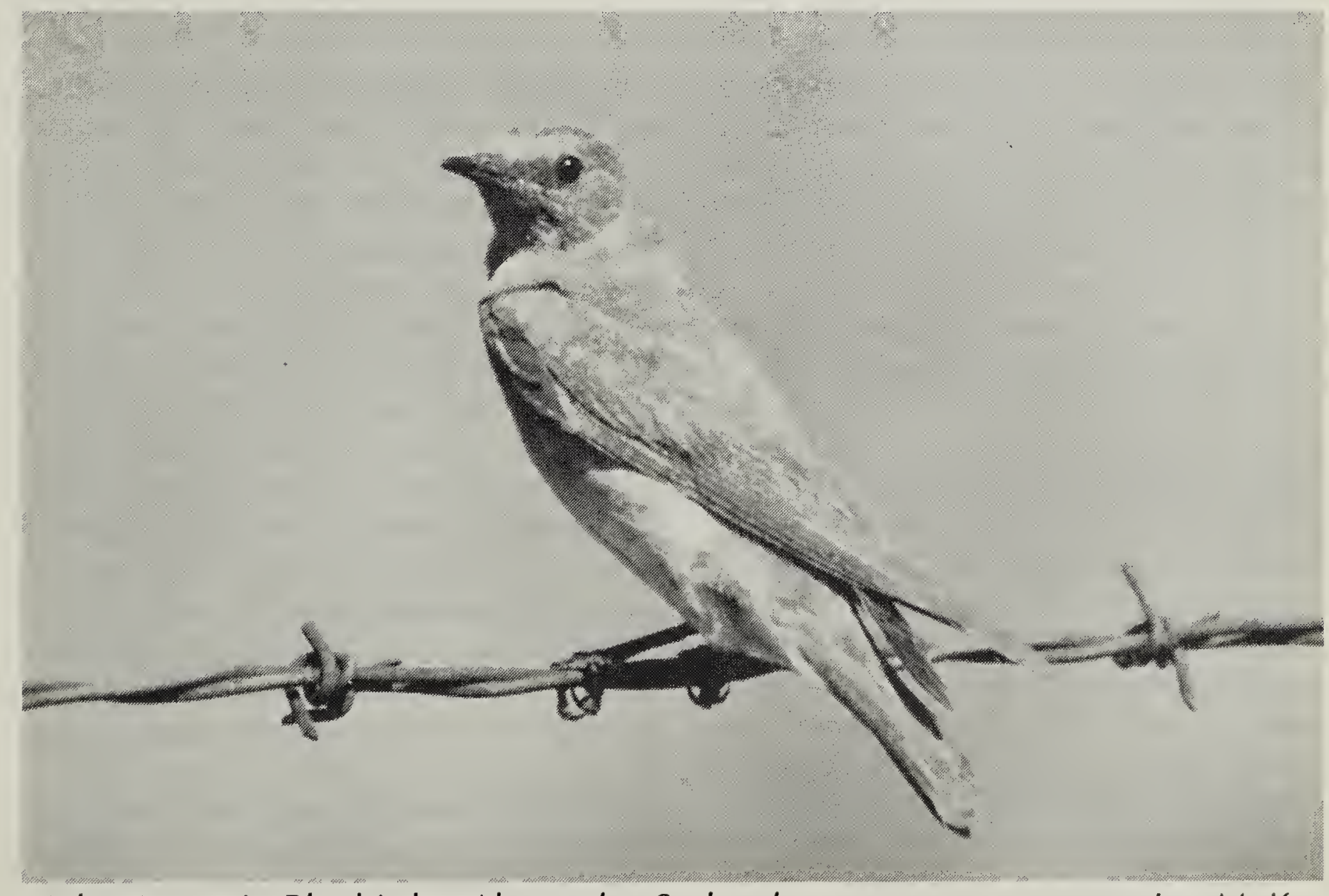




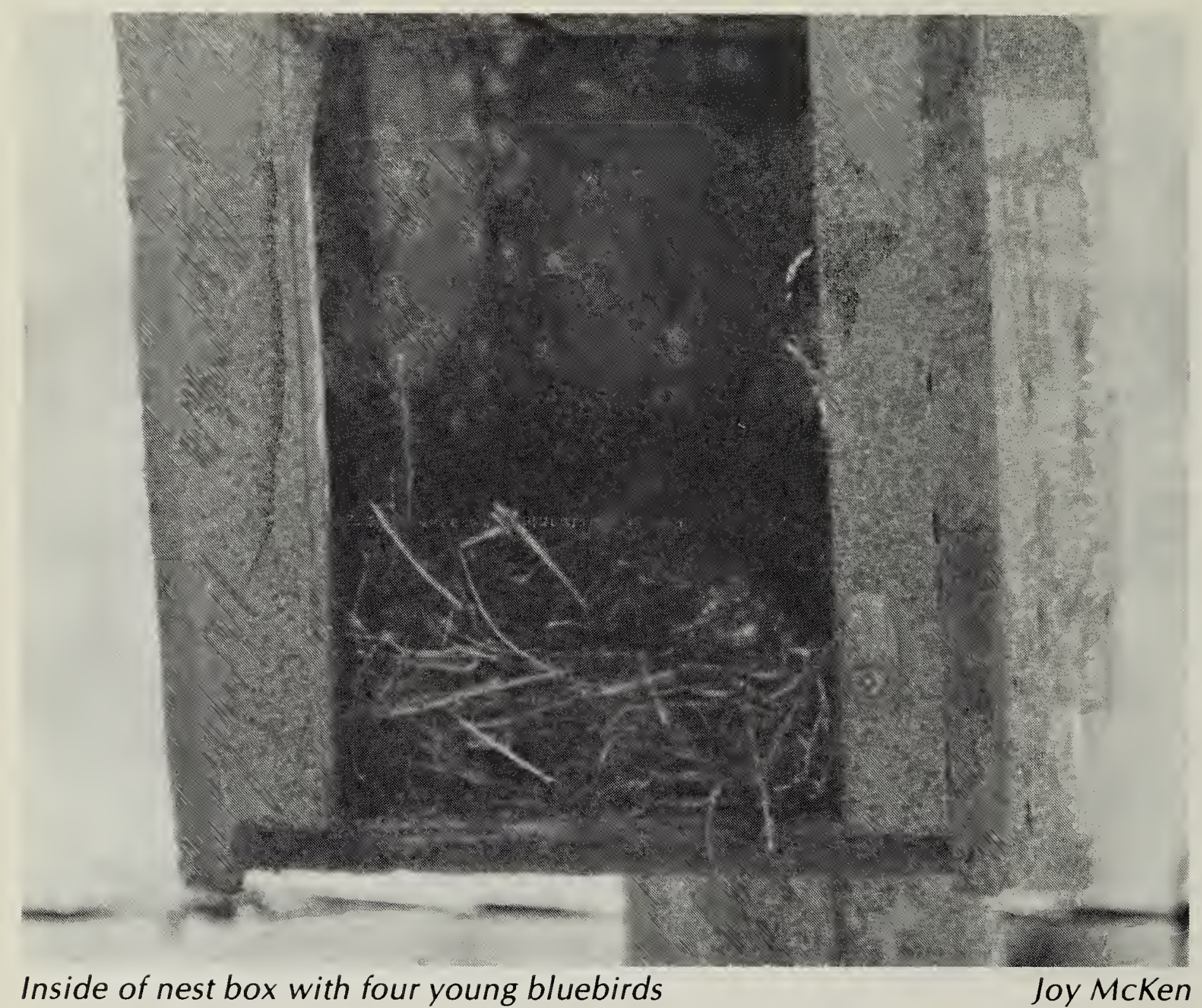

In following years bluebirds nested in places such as the twine box of the binder and the interior of the combine. One year we were saddened when a pair of dead bluebirds flowed into a pail with oats from the bin. They had entered the bin through a knothole and could not find their way out.

About 1950 I mounted a bird house on a post $10 \mathrm{~m}$ from the kitchen window. The bluebirds used this house for about 10 years. Then one year there was a snow storm after the bluebirds were back investigating their house. They were not seen after that. That was the end of the first chapter in my bluebird experience. My parents moved from the farm, and I had already been away for a few years employed in Alberta.
In 1982 I returned to Abernethy and in 1984 I decided to renew my bluebird activity. I built 12 houses and mounted them on fence posts about $300 \mathrm{~m}$ from a vacant farm yard. I had no bluebirds in 1984, one nest in 1985, none in 1986 and one in 1987. I also had about six Tree Swallow nests each year. In 1987 , the only year in which the bluebirds attempted a second brood, House Sparrows destroyed the eggs. I decided it was time to move the houses to a better habitat, increase the number of houses and change to the paired house system. In the summer of 1987 I built 12 more houses and moved all the houses to a new location for the 1988 season.

\section{The 1988 Bluebird Trail and Results}

The houses were located on fence posts bordering a 320 -acre grazed pas- 
Table 1. RESULTS FROM ABERNETHY BLUEBIRD TRAIL, 1988.

The trail was $1.5 \mathrm{mi}$. $(2.4 \mathrm{~km})$ long and had 12 pairs of houses.

\section{Mountain Bluebird Mountain Bluebird Tree Swallow first brood second brood}

$\begin{array}{llll}\text { Nestings } & 6 & 6 & 9 \\ \text { Eggs } & 34 & 28 & 51 \\ \text { Hatched } & 33 & 26 & 50 \\ \text { Fledged } & 33 & 26 & 46 \\ \text { Average clutch } & 5.67 & 4.67 & 5.67 \\ \text { Hatching rate } & 97 \% & 93 \% & 99 \% \\ \text { Date of first egg: range } & 1 \text { May - 21 May } & 15 \text { June }-5 \text { July } & 26 \text { May - } 17 \text { June } \\ \quad \text { median } & 13 \text { May } & 28 \text { June } & 27 \text { May } \\ \text { Incubation period } & 13 \text { days } & 13 \text { days } & 13 \text { days } \\ \text { Hatch to fledge period } & 19-21 \text { days } & 18-20 \text { days } & 18 \text { - 20 days }\end{array}$

ture with a few small aspen groves (good bluebird habitat). The 24 houses were arranged in 12 pairs on half the perimeter of the pasture. The houses in each pair were about $10 \mathrm{~m}$ apart and the pairs about $200 \mathrm{~m}$ apart. I monitored the houses every 5 days which allowed me to make good estimates of the incubation period and the period during which the young were in the houses.

It was a good year for bluebirds with 59 fledged compared to 46 Tree Swallows. The results are summarized in Table 1. Not all the bluebirds had second broods although the table seems to indicate that. Four out of six had second broods; the other two late broods were by newcomers to the houses. Hence there were eight pairs of bluebirds responsible for the 12 nestings. The four pairs which had two broods stayed in the same boxes for the second broods. I did not clean out the old nests between broods; the new nests were built on top of the old. The two pairs which did not have second broods were the latest nesters and had the smallest clutches. The most common clutch size was six for first nesting attempts of both bluebird and Tree Swallow, and five for second clutches of bluebirds. The hatching rate given in the table is also the fertility rate as there was no predation of eggs.

The earliest bluebird started building about 18 April, finished about 22 April and laid the first egg 1 May. The fastest worker started about 3 May, finished about 7 May and laid the first egg 10 May. The slowest worker started about 22 April, finished about 3 May and laid the first egg 21 May. The average period from start of nest building to first egg was about 12 days for first broods, and from fledging to first egg of second brood was about 9 days.

The incubation periods are based on several instances where the eggs were hatching on the monitoring day. There were three nests for swallows, three for first brood bluebirds and two for second brood bluebirds. In every case the period was 13 days.

Table 2 gives the nesting count in terms of house pairs. The paired house system worked well. There was no evident conflict between swallows and bluebirds, and there were no cases of the same species in both houses of a pair. 


\begin{tabular}{|c|c|c|}
\hline Occupants & $\begin{array}{l}\text { Bluebird } \\
\text { 1st brood }\end{array}$ & $\begin{array}{l}\text { Bluebird } \\
2 \text { nd brood }\end{array}$ \\
\hline Bluebird - swallow & 3 & 4 \\
\hline Bluebird - bluebird & 0 & 0 \\
\hline Swallow - swallow & 0 & 0 \\
\hline Bluebird - vacant & 3 & 2 \\
\hline Swallow - vacant & 5 & 4 \\
\hline Vacant - vacant & 0 & 1 \\
\hline Swallow - wren & 1 & 1 \\
\hline
\end{tabular}

more open, having wide entrances on two or more sides compared to the circular 1.5-inch $(38 \mathrm{~mm})$ entrance of the conventional houses. The entrances are also more hidden by the overhanging roof. I had hoped that bluebirds would show a preference for the test houses, and Tree Swallows for the conventional, thus further reducing competition between them. For the 1988 season $22 \%$ of swallow nestings and $33 \%$ of bluebird nestings were in the test houses. It will likely take about 5 years before valid conclusions can be drawn.

\section{Looking Ahead}

I built 24 more houses for the 1989 season; they will complete the trail around the perimeter of the pasture. This brings the total to 48 houses (24 pairs) on a $3-\mathrm{mi}$. $(4.8 \mathrm{~km})$ loop, and will not increase the walking distance compared to covering half the loop and then backtracking.

The 1988 season was the beginning of an on-going experiment in birdhouse design. Two thirds of the houses are conventional; the others are test houses of three different designs. They are

There are three factors which I believe contributed to bluebird success this year: good habitat, paired houses, and concentration of houses. With 16 houses ( 8 pairs) per mile ( 10 houses per $\mathrm{km})$, the bluebirds can nest in loose colonies which they seem to like. ${ }^{2}$

1 TAVERNER, P.A. 1945. The birds of Canada, new and revised edition. Toronto: Musson Book Co. Ltd.

${ }^{2}$ WALLEY, W.J. and W.L. CLARK 1985. The Eastern Bluebird at Dauphin, Manitoba. Blue Jay 43(3):160-168.

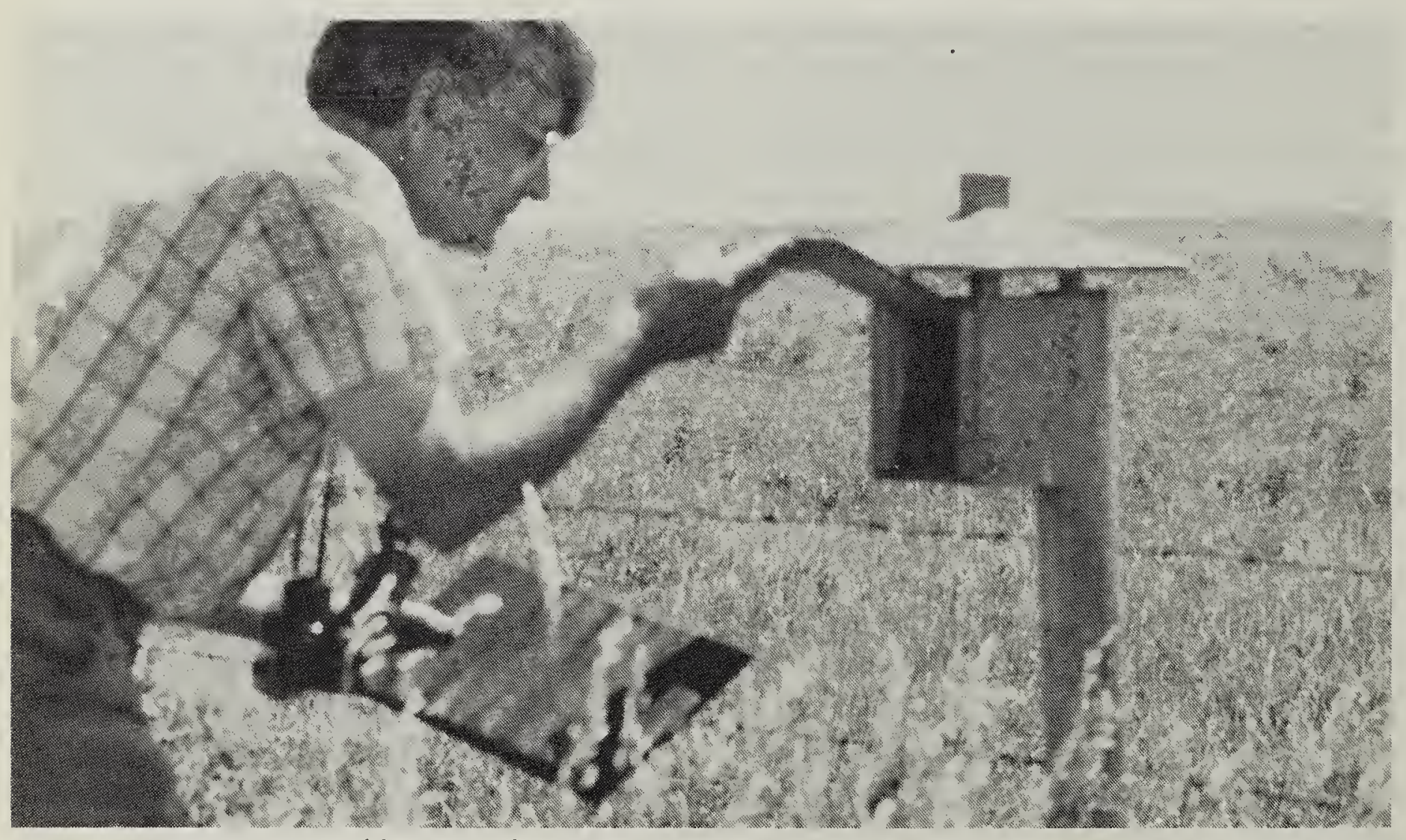

